\title{
Understanding of Eight Grade Students about Transformation Geometry: Perspectives on Students' Mistakes
}

\author{
Gulfem Sarpkaya Aktaş ${ }^{1}$, Melihan Ünlü ${ }^{1}$ \\ ${ }^{1}$ Faculty of Education, Aksaray University, Aksaray, Turkey \\ Correspondence: Gülfem Sarpkaya Aktaş, Faculty of Education, Aksaray University, Aksaray, Turkey.
}

Received: March 1, 2017

Accepted: April 11, 2017

Online Published: April 12, 2017

doi:10.11114/jets.v5i5.2254

URL:https://doi.org/10.11114/jets.v5i5.2254

\begin{abstract}
People need the idea of transformation geometry in order to understand the nature and environment they live in. The teachers should provide learning environments towards perceptual understanding in symmetry training and development practice skills of the students. In order to make up such a learning environment, teachers should have information about the mathematical structure of the concept of symmetry, the difficulties the students encounter while learning, misconceptions and the causes. Therefore, the challenges and the common mistakes the $8^{\text {th }}$ grade middle school students encounter about the transformation geometry was analysed in the study. The study was conducted using mixed method designs with $1258^{\text {th }}$ grade students. At the end of the study, it was observed that the students understood that the translation transformation is a movement of replacement, but they had difficulty in the topics such as the direction of the transformation and the position of the shape within the transformation. A misconception was developed for the reflection by confusing the similarity with the congruence property of the shapes. It was detected that the students had difficulty in identifying the equation of the axis of symmetry for the images of the shapes under reflection, confused the rule that the points intersecting with the symmetry of the shape within the reflection should intersect with the image under transformation and they made mistakes since they couldn't explore the relationship between symmetry axis in regular polygons and sides. They had problems in finding and practicing the angle of rotation about rotational transformation and also. In the study, learning environments were recommended towards overcoming these challenges for teachers and coursebook writers and improving conceptual information and the skill to practice these concepts.
\end{abstract}

Keywords: Transformation geometry, students' mistakes, difficulties in learning

\section{Introduction}

The main purpose in Mathematic lessons in middle schools is to gain students problem solving skills, reasoning, providing relationships (Baykul, 2009) and communication (Ministry of National Education [MoNE], 2013). All these skills can be improved by encouraging students to do maths. Doing maths is a process to develop methods to solve the problems, to practice these methods, to see whether they give any result and to test the reliability of the given answers. On the basis of doing maths exists understanding mathematics. Understanding can be described as the measuring the quantity of quality of the connections of any idea with other ideas (Van De Walle, Karp \& Bay-Williams, 2012). While thinking about perceiving a mathematical idea, it is necessary to define operational and conceptual understanding which can be classified as the types of mathematical information and which are the reflection of relational and instrumental understanding, Skemp (1976) produced, in mathematics education. Conceptual understanding is the perception about basic ideas and relations as regards a topic. Operational understanding is to know the symbols of mathematical terms and the information about the rules and expressions used while making mathematical operations (Van De Walle et al., 2012). Conceptual understanding is a phenomenon based on the relational skill. The relational understanding can be described as making connections of mathematical concepts with each other, the concepts in other disciplines and daily life (Baykul, 2009). In order to provide conceptual understanding, these connections need to be included in mathematics lessons.

One of the most important applications of mathematics in daily life is the concept of transformation geometry. People need this concept so as to understand the nature and environment they live in. Since it helps students to understand their situations in daily life, it is important to teach it in primary and middle schools (Knuchel, 2004). This concept is a necessary mental tool to be able to analyse mathematical situations (NCTM, 1991). It enables students to make up rules and patterns, make explorations, be more motivated to do better works and gain rich experiences by doing maths 
(Knuchel, 2004). Rotation, translation, reflection concepts within geometrical transformations are used in daily life, architectural designs, art and technology. In general terms, it could be said that geometric transformations are functional and isometric structures (Aksoy \& Bayazit, 2009; Zembat, 2013a; Zembat, 2013b; Yavuzsoy Köse, 2013; Hollebrands, 2003). In the literature, it was noticed that transformation geometry is used with the same meaning as the concept of symmetry in the studies (Aksoy \& Bayazit, 2009). In this study, only the reflection transformation represents the concept of symmetry and the other transformations are described as translation and rotational transformations.

Transformation geometry is important in terms of developing artistic and aesthetic feelings with the awareness of the beauties in nature (Aksoy \& Bayazit, 2009). Many renown artists in the 20th century, in their art works, used the designs in which transformation geometry was applied (Knuchel, 2004). The artistic works become more attractive when transformation geometry is used (Conway, Burgiel, Strauss \& Goodman, 2008).

Learning the concept of transformation geometry is important for students to make analysis and synthesis, problem solving and to think spatially (Aksoy \& Bayazit, 2009). Besides, it enables students to organize the things and events around them, thus enabling them to improve their qualitative comprehension about the outer world (Knuchel, 2004). The students' skill to understand transformation geometry will be precursor to understand other mathematical concepts. For instance, Wheatley (1998) determined that the concept predicting the students' strategy to make four operations are the mental skills to transform the geometric shapes and things (Aksoy \& Bayazit, 2009). Additionally, transformation geometry, algebra and assessment-learning fields are closely connected with integers. It is also effective for students to gain reasoning skill (Van De Walle et al., 2012). It is necessary for algebra in the usage of coordinate axes in the transformation of the shapes in proportional reasoning or in enlarging and reducing a design, for assessment and learning in identifying the equation of the coordinate axes and for integers in finding the images of the given points in the coordinate axes under transformation.

Because of the cumulative structure of mathematics, some misconceptions inevitably turn out if conceptual learning is not provided. The definition of misconception is explained differently in the literature. Some of these definitions are as such; mistaken ideas (Fisher, 1983), wrong practise (Elby, 2001), the perception or understanding which is distanced from the main theme the experts agree on (Ubuz, 1999; Zembat, 2008).Misconception is also described as students' perception which systematically produces mistakes (Smith, diSessa \& Roschelle,1993; Zembat, 2008). They are not the mistakes themselves, but the reason of them. It can be easily noticed that in almost each topics of mathematics, there are mistakes due to misconceptions the students have (Bingölbali \& Özmantar, 2009). One of the first things to do for providing an effective learning is to identify the students' misconceptions (Ryan \& Williams, 2007).

When the studies were looked up, it was noticed that the students had difficulties and misconceptions about the transformation geometry. These misconceptions are generally the mistakes such as finding the reflection axis (Kaplan \& Öztürk, 2014; Hacısalihoğlu-Karadeniz, Baran, Bozkuş \& Gündüz, 2015; Yavuzsoy Köse \& Özdaş, 2009), slope reflection on axis, finding the image of the objects, specifying the equation of the distances between the object itself and its image (Yavuzsoy Köse, 2012) and defining the concept of reflection transformation (Hacisalihoğlu-Karadeniz, et al.,2015).Son (2006) indicates that teacher candidates often confuse reflection and rotation in their work. However, no study was found covering the whole topic of transformation geometry in the literature. For instance, Yavuzsoy Köse (2012) focused in her study on the mistakes students made towards their information on symmetry. Kaplan and Öztürk (2014) tried to show the students' mistakes with the questions they prepared in accordance with the students' thinking levels by using the concepts of reflection transformation. It would be a very important contribution for the literature to include all of the transformation concepts and to show the students' mistakes and their comprehension leading to these mistakes.

The fact that the students have misconceptions is not a situation caused only by the students. In this case, it is significant to show the difficulties the students encounter while learning transformation geometry and to identify the mistakes since this could give an idea about which concepts should special teaching strategies be made up for the teachers teaching this topic. Coursebooks are indispensable for the learning environments as well as teachers. Coursebook writers can include the activities and the content that will vanish these mistakes about the transformation geometry in their books when they are aware of the mistakes and misconceptions the students have. Therefore, research is considered to be important.

\subsection{Concept and Concept Teaching}

The concept is described as a general and abstract idea including the common characteristics of the objects (Ubuz, 1999) or events and as the particle of information representing the common characteristics of phenomenon and different objects structured in human brain (Ülgen, 2001). Because of the cumulative structure of mathematics and with refence to this, the spiral structure of the teaching program (Ersoy, 2006), it is difficult to define other concepts without teaching the concepts in connection with any concept. Especially in primary and middle schools, it is often not possible for a student, who hasn't structured any previous concept, to follow the topics. The students mostly have trouble and make 
mistakes in mathematics. In describing the difficulties encountered in teaching mathematics, the terms such as difficulty, misconception and mistake are used. Since the difficulty explains the challenges encountered in mathematics, it includes misconception and mistake (Bingölbali \& Özmantar, 2009). The relationship between misconception and mistake is given in the introduction. The basic concept of the study, transformation geometry and its sub-concepts are explained below.

\subsection{Transformation Geometry}

Transformation geometry was first mentioned in the seminar named Erlangen program by Christian Felix Klein in 1872. Klein defined geometry as the shapes of which properties remain stable under the transformations (Burton, 2011). Dodge (2012) defined a transformation on the plane is one-to-one correspondence from the plane onto itself. According to these definitions, isometric transformations, which keep the properties in geometry, came into prominence (Zembat, 2013). Namely, according to Klein's thought, the properties kept in the interpretation of the transformations should be studied (Yavuzsoy Köse, 2013). Transformation geometry is a kind of transforming process and it could be said that it is a function (Aksoy \& Bayazit, 2009; Zembat, 2013a, 2013b; Yavuzsoy Köse, 2013; Hollebrands, 2003). Here the domain is a geometric shape or an object; function is the movement of transformation; and the image set is the activated shape of the initial shape according to the parameter taken. Students conceptualized transformations as "physical motions"(Edwards, 2003)

\subsection{Reflection Transformation}

One of the most important application fields in actuel life of reflection within the content of mathematics is the concept of symmetry. Symmetry is a important tool to understand the nature and the environment and is used in many fields ranging from art to architecture (Aksoy \& Bayazit, 2009).

Symmetry has two different meanings. The first meaning which geometric and algebraic patterns make up and the meaning of balance and ratio used in the association of the parts within a whole in harmony. The second meaning is associated with the order of symmetry, harmony, aesthetics, beauty and perfection (Yavuzsoy Köse, 2013). According to Conway, Burgieland Goodman Strauss (2008) by using symmetry the mysterious world of mathematics can be shown with visual objects, its artistic aspect could be explored and also its visual beauty could be revealed.

Reflection transformation is also the basis of the comprehension of the topics in Analitic geometry. The reflection of any geometric shape is made up by intersecting lines from every angle on the shape and projecting these angles on the other side of the axis. Thus, the projected geometric shape and the reflected according to axis are of equal length and they are the same in basic properties, but different in terms of location and direction.

\subsection{Translation Transformation}

Translation transformation is the image taken according to the described function in a straight line and in the same direction of a vector or a geometric object. Namely, it is function that matches the plane with another by means of one to one correspondence (Zembat, 2013). The movement of a geometric shape or an object from one place to another in a specific rotation and direction is called translation transformation (Aksoy \& Bayazit, 2009).

In the conceptualising and naming translation transformation mathematically, three properties could be utilized. The first one is that translation transformation keeps the internal dynamic, that is edge length, angles and direction of a geometric shape. The second is that the properties of every point on geometric shapes are the same as among the matched points after the transformation. Therefore, some specific points of a geometric shape are not applied to translation transformation and the image of every point under this transformation is found. Thirdly, translation transformation with the zero vector matches the geometric object on the plane with itself (Zembat, 2013).

\subsection{Rotation Transformation}

Rotation transformation is the function that fixes every one of the points on the plane with another point on the plane. Martin (1982) describes rotation transformation as a function that covers and one to one correspondences all points on the plane with the help of a central point and angle with the points on the plane. Rotation transformation keeps angles and distances which are the dynamics of the plane.

In the interpretation of solids, one of the subjects of geometry, rotation transformation is used. A student who sees that when a right triangle is rotated $360^{\circ}$ around one of the legs, a cone is obtained, when a rectangular is rotated $360^{\circ}$ around one of its lines, a cylinder is obtained and when a semicircle is rotated $360^{\circ}$ around its diameter, a sphere is obtained can be able to learn solids conceptually (Aksoy \& Bayazit, 2009).

\subsection{The Purpose of the Study}

The purpose of the study is to show the mistakes and the challenges of the middle school students in the subject of transformation geometry. 


\section{Method}

This study was conducted by using mixed method research made up combining both qualitative and quantitative methods. This method was used in order to explain quantitative data with qualitative samples. Of the mixed method designs, sequential explanatory design was used. Sequential explanatory design involves two different integrated phases. The result for the study question is firstly searched with quantitative research and afterwards the qualitative results which will help to explain quantitave results are searched (Creswell \& Plano Clark, 2015). According to the purpose of the study, by the test of transformation geometry, the mistakes the students often made were revealed in the first place. Subsequently, the data was collected by the interview method in order to explain how they produced thinking for these mistakes.

\subsection{Participant (Subject) Characteristics}

This study was conducted with 125 students of 8th grade studying in three different public schools in 2013-2014 education year. For the determination of the participants, criterion sampling from the purposive sampling methods was used. Criterion sampling means that observation units in a study consist of people, objects and conditions having some specific characteristics (Büyüköztürk, Kılıç-Çakmak, Akgün, Karadeniz \& Demirel, 2012). The selection of 8th grade students is a criterion. The reason of selecting this criterion is to provide learning environments towards all acquisitions of the participant students about the concept of transformation geometry. Among those who were applied transformation geometry test, 11 students were interviewed. These students were selected because they made more mistakes among the other participant students.

\subsection{Data Collection Tool}

As data collection tool, a concept test of transformation geometry of which reliability and validity was determined was used. The test used was prepared by the researchers in accordance with the acquisitions about transformation geometry in the curriculum of Turkey Ministry of National Education and the literature. Test articles consist of the questions about reflection about transformation geometry, symmetry according to a line, rotation transformation, translation transformation and symmetry according to a point. In the test, 8 open-ended and 8 multiple choices in total 16 questions exist. A table of specification was prepared with the purpose of determining if the prepared questions measured the required properties. In table 1, the table of specification is given specifying the questions belong to the acquisitions.

Table 1.Table of specification of the concept test of transformation geometry

\begin{tabular}{|c|c|c|}
\hline Acquisitions & Class level & Questions \\
\hline $\begin{array}{l}\text { Draws the image of point, line segment and other shapes under translation } \\
\text { on the plane }\end{array}$ & $7^{\text {th }}$ grade & $5,14,16$ \\
\hline $\begin{array}{l}\text { Discovers each point on the plane subject to a transformation in the same } \\
\text { direction and size in translation and the shape and its image } \\
\text { arecorrespondent. }\end{array}$ & $7^{\text {th }}$ grade & $5,14,16$ \\
\hline $\begin{array}{l}\text { Makes up the image of point, line segment and other shapes on the plane } \\
\text { occurring as a result of reflection. }\end{array}$ & $7^{\text {th }}$ grade & $2,4,7,11,13,15$ \\
\hline $\begin{array}{l}\text { Discovers the distances to symmetry line of the corresponding points on } \\
\text { the shape and its images is equal in the reflection and the shape and its } \\
\text { images are correspondent. }\end{array}$ & $7^{\text {th }}$ grade & $1,3,6,7,11,15$ \\
\hline $\begin{array}{l}\text { Makes up the images of point, line and other planary shapes under } \\
\text { transformation }\end{array}$ & $8^{\text {th }}$ grade & $8,9,12$ \\
\hline $\begin{array}{l}\text { Discovers every one of the points on the shape subjects to clockwise or } \\
\text { anti-clockwise direction with a specific angle in the rotation and the shape } \\
\text { and its image are correspondent. }\end{array}$ & $8^{\text {th }}$ grade & 8,10 \\
\hline $\begin{array}{l}\text { Draws and determine the images of translation of a polygon in a coordinate } \\
\text { system, reflection in one of its axis, tranlaslation in any line and rotation } \\
\text { around its origin. }\end{array}$ & $8^{\text {th }}$ grade & 11,16 \\
\hline
\end{tabular}

The test prepared in order to provide the content validity of the concept test of transformation geometry was studied by math teachers and educators and made available for the pilot scheme by making necessary corrections. The prepared test was applied on 102 students in a middle school in a city. Formed after item analysis,the concept test of transformation geometry mean score was calculated to be 4.9. Mean difficulty index was found to be 0.60 and mean discrimination index was found to be 0.39 . These values show that the test is at the required difficulty level and a good test.Besides, KR-20 reliability coefficient was calculated and the result was found 0,70 . For the open ended questions in the concept test of transformation geometry, necessary corrections were made with the help of experts' view.

\subsection{Collecting Data}

The concept test of transformation geometry of which reliability and validity was proved was conducted with 110 students of 8th grade studying in three different public schools in 2013-2014 education year. The common mistakes 
from the answers given were found out and of the students making these mistakes, 11 students were clinically interviewed. The interviews lasted for 20-25 minutes. By making clinical interviews, more detailed data about the patients were obtained.

\subsection{Analysis of Data}

In the analysis of open-ended questions in the test, categorisation was made in terms of accuracy. These categories were as such "completely correct", "partly correct", "wrong" and "blank". In the assessment of the answers of the questions participating in the study, the criteria used are as such:

Completely correct: The explanations which can be regarded as scientifically true and proper

Partly correct: The explanations are true in part, but they are insufficient according to the right answer.

Wrong: The answers which are not scientifically true and in which there are wrong explanations.

Blank: The category in which there is no answer or explanations of the students.

Category examples and explanations for the question 8 are given in Table 2 .

Question 8

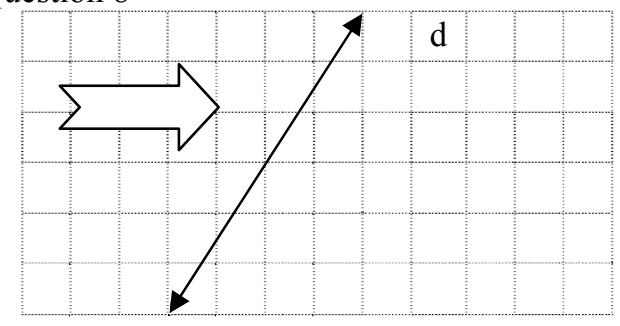

Could you find and draw the reflection of the shape according to the $\mathrm{d}$ line?

Table 2. Category samples

Question 8
Completely
correct
correct

Explanation

The student's drawing was accepted completely correct for the open-ended question "find the reflection of the given shape according to d line". While the shape was transformed according to the oblique reflection, the shape was drawn by taking vertical projection of the based points according to oblique symmetry axis.

For the question asked the image of the given shape under the reflection in oblique symmetry axis, the shape the student drew was right in direction, but since it is different as size and besides, since it was not in equal distance to the based points on the shape, it was taken into category as partly correct.

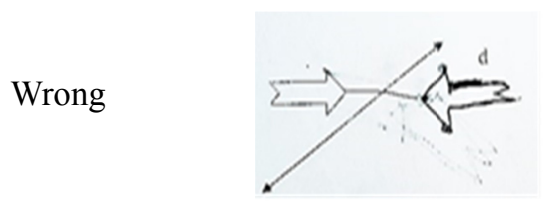

The student answered this question by taking the vertical symmetry axis into consideration. There is lack of information about oblique symmetry axis.

The anaylsis of open ended questions was assessed separately by the reseachers. The controversies were resolved among the researchers by talking about and a common view was tried to be reached. The formula of Miles and Huberman (1994) was used to calculate inter-rater reliability and it was calculated as $84 \%$ for the classification.

In the analysis of multiple choice questions, for the right answer the students gave to each question, the score was 1 and for the wrong and blank ones, it was 0 . In the analysis of the data, descriptive analyses were used. Moreover, the answers were profoundly studied and the samples from the common mistakes the students made were shown. In order to determine the reasons of the common mistakes, direct quotations were given from the clinical interviews of 11 students chosen according to the answers given for the test. 


\section{Findings}

\subsection{Findings about Open-ended Questions}

The answers given for the open-ended questions in the concept test in transformation geometry were assessed as completely correct, partly correct, wrong and blank and tabulated by the researchers

\subsubsection{Findings about the concept of Symmetry according to a Point}

In the $11^{\text {th }}$ question, it was tried to determine whether the students took symmetry according to the origin of the coordinate system. The percentage (\%) and frequency (f) of the answers for the questions are given in the table below.

Table 3. The percentage (\%) and frequencies (f) of the students' answers to the question about taking symmetry in a point

\begin{tabular}{lllllllll}
\hline & Completely correct & \multicolumn{2}{l}{ Partly correct } & \multicolumn{2}{l}{ Wrong } & \multicolumn{2}{l}{ Blank } \\
\hline Question 11 & $\mathrm{f}$ & $\%$ & $\mathrm{f}$ & $\%$ & $\mathrm{f}$ & $\%$ & $\mathrm{f}$ & $\%$ \\
& 34 & 27.2 & 11 & 8.8 & 58 & 46.4 & 22 & 17.6 \\
\hline
\end{tabular}

$27.2 \%$ of the students $(\mathrm{f}=34)$ answered to the question "completely correct", $8.8 \%(\mathrm{f}=11)$ "partly correct" $46.4 \%$ ( $\mathrm{f}=$ 58 ) "wrong" and $17.6 \%$ ( $f=22)$ left the question blank. These results showed that the students failed to apply reflection of a point. More than half of the students involved in the sample couldn't answer the question correctly. The students making "partly correct" generally made mistake on the size of the shape. The majority of the students making "wrong" made mistakes such as the rotation of the shape or while making reflection not being able to congruent the points with which the shape is congruent with the horizontal axis. Some examples from the wrong answers of the students for this question are given in Table 4.

Table 4. Examples from the students' answers

Partly correct

\subsubsection{Reflection in a Line and Findings about Symmetry Axis}

Third, eight. and thirteenth questions aim to determine the symmetry of a given shape in a line.

Table 5. The percentage (\%) and frequencies (f) of the students' answers to the question about taking symmetry in a line

\begin{tabular}{lllllllll}
\hline & \multicolumn{2}{c}{ Completely correct } & \multicolumn{2}{l}{ Partly correct } & Wrong & \multicolumn{3}{l}{ Blank } \\
\hline & $\mathrm{f}$ & $\%$ & $\mathrm{f}$ & $\%$ & $\mathrm{f}$ & $\%$ & $\mathrm{f}$ & $\%$ \\
Question 3 & 97 & 77.6 & 11 & 8.8 & 10 & 8 & 7 & 5.6 \\
Question 8 & 10 & 8 & 16 & 12.8 & 77 & 61.6 & 22 & 17.6 \\
Question 13 & 8 & 6.4 & 15 & 12 & 71 & 56.8 & 31 & 24.8 \\
\hline
\end{tabular}

One of the questions measuring to take symmetry in a line, $3^{\text {rd }}$ question was answered "completely correct" by $77.6 \%$ (f $=97)$ of the students, "partly correct" by $8.8 \%(\mathrm{f}=11)$ of the students, "wrong" by $8 \%(\mathrm{f}=10)$ of the students and left the question blank by $5.6 \%(\mathrm{f}=7)$ of the students. When studied the percentage of answering this question, it can be said that the students generally had information about the fact that the dimensions of the given shape under reflection would remain the same. When we studied into the students' solutions in the category of "partly correct", it was observed that the students knew that the shapes given in the question were not one to one image of theirs under reflection, but they had difficulty in explaining. Also, it was seen that they reported and a functional knowledge-based idea as such "when we fold the paper, the shapes do not overlap." When studied the students' answers in the category of "wrong", it was understood that they tried to contact relationship with the similarities and equality of the triangles (see Table 6).

One of the questions measuring to take symmetry in a line, $8^{\text {th }}$ question was answered "completely correct" by $8 \%(\mathrm{f}=$ $10)$ of the students, "partly correct" by $12.8 \%(\mathrm{f}=16)$, "wrong" by $61.6 \%(\mathrm{f}=77)$ and left blank by $17.6 \%(\mathrm{f}=22)$. It was detected that the students who answer "partly correct" to the $8^{\text {th }}$ question didn't make mistake about finding the rotation of the shape under reflection in general. The points that the students made mistakes for this question are as such: in the first place, they thought reflection as if it was translation and they didn't make any change of its rotation but its position. Another mistake appeared in the match of the point taken on the first shape with the point whose image was taken under reflection. In other words, while the image of a point taken on the shape was being found, the students made mistakes in determining equal distances which would cut symmetry axis vertically. This mistake also shows that 
there was wrong about the perception of oblique symmetry axis.

Although the $3^{\text {rd }}$ and $8^{\text {th }}$ questions are about oblique symmetry axis, when the percentage of the correct answers was studied, it was seen that the third question was answered correctly with a rate of $76.6 \%$ and the eighth question was answered correctly by $8 \%$. The reason why the $8^{\text {th }}$ question had such a low rate in finding the correct answer might be that the students themselves had to draw the reflection of the closed shape according to the oblique symmetry axis. The reflection of the closed shape given in the $3^{\text {rd }}$ question took place in the main question. The students do not need to draw a shape since the question asks them to answer whether the image of the given shape under reflection is the shape given or not.

One of the questions measuring to find symmetry axis, $13^{\text {rd }}$ question was answered "completely correct" by $6.4 \%(\mathrm{f}=8)$ of the students, "partly correct" by $12 \%$ ( $\mathrm{f}=15)$, "wrong" by $56.8 \%$ ( $\mathrm{f}=71)$ and left blank by $24.8 \%$ ( $\mathrm{f}=31$ ). More than half of the students gave "wrong" answers or left the question blank for this question. They didn't have enough information about symmetry axis of parallelogram shape. The answers stating no explanation by thinking parallelogram has no a symmetry axis are included in the category of "correct". When studied the wrong answers, it was observed that the students generally made transformation of parallelogram shape by drawing an imaginative symmetry axis apart from the shape. Also, they divided parallelogram into two equal part by drawing diagonal lines. Based on this, they stated that the parallelogram has two symmetry axis.

The examples from the mistakes the students made in the $3^{\text {rd }}$ questions are shown in Table 6 and the examples from the common mistakes in the $8^{\text {th }}$ and $13^{\text {rd }}$ questions are shown in Table 7.

Table 6. Examples from the students' answers for the $3^{\text {rd }}$ question.

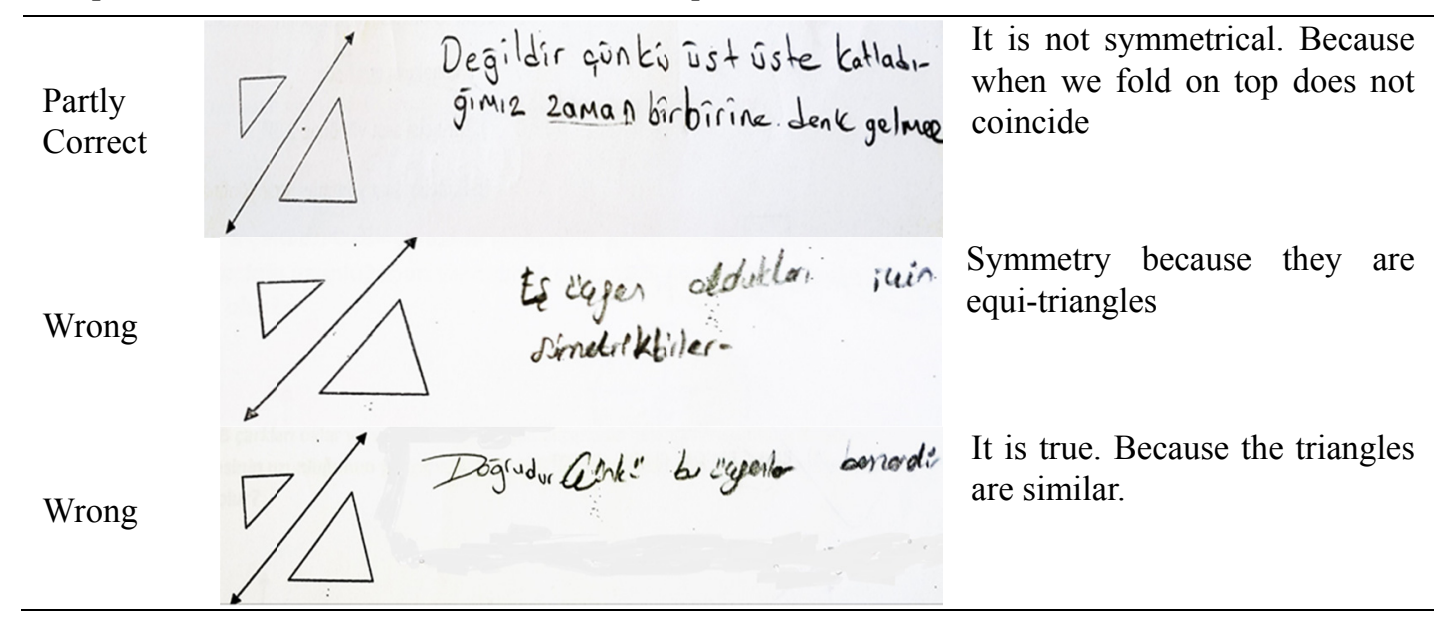

Table 7. Examples from the students answers for the $8^{\text {th }}$ and $13^{\text {rd }}$ questions

Question 13

\subsubsection{Findings about Rotational Transformation}

The analysis of $10^{\text {th }}$ and $12^{\text {th }}$ open-ended questions about rotational transformation are given below. The questions are as such: 


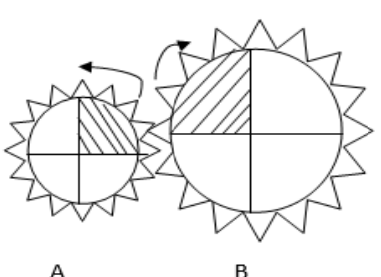

$\mathrm{A}$ and $\mathrm{B}$ wheels are getting rotated in the direction of the arrows. The perimeter of $A$ wheel is half of the one of $B$ wheel. If $A$ wheel is rotated $180^{\circ}$, how is the image of $\mathrm{B}$ wheel?

Qestion 12: Find the new coordinates of $\mathrm{E}(6,0)$ point by rotating $180^{\circ}$ anticlockwise.

Table 8 . The percentage (\%) and frequencies (f) of the students' answers to the question about rotational transformation.

\begin{tabular}{lllllllll}
\hline & \multicolumn{1}{l}{ Completely correct } & \multicolumn{1}{l}{ Partly correct } & Wrong & \multicolumn{3}{c}{ Blank } \\
\hline & $\mathrm{f}$ & $\%$ & $\mathrm{f}$ & $\%$ & $\mathrm{f}$ & $\%$ & $\mathrm{f}$ & $\%$ \\
Question 10 & 32 & 25.6 & 4 & 3.2 & 36 & 28.8 & 53 & 42.4 \\
Question 12 & 52 & 41.6 & 1 & .8 & 30 & 24.0 & 42 & 33.6 \\
\hline
\end{tabular}

One of the questions measuring rotation, $10^{\text {th }}$ question was answered "completely correct" by $25.6 \%(\mathrm{f}=32)$ of the students, "partly correct" by $3.2 \%(f=4)$, "wrong" by $28.8 \%(f=36)$ and left blank by $42.4 \%(f=53)$. It was noticed that the answers including in the category of "partly correct" were generally found to be correct for the shaded area of B wheel, whereas they were found to be wrong for the shaded area of A wheel. As stated in the example, it was seen that the students determined correctly to the image of B wheel as a result of rotating A wheel $180^{\circ}$, but the image was drawn wrongly in the rotation of A wheel $180^{\circ}$ (see Table 9). It was also seen that the students who gave wrong answers didn't take the perimeter of circle of B wheel into account and thus calculated the angle of the rotation wrongly and when a wheel was rotated, they didn't think about the process of the rotation of the other wheel. For this question, about half of the students preferred not to answer, that is, they preffered to leave the question empty. It could be said that the students have some lack of information about rotation and that they do not feel confident.

One of the questions measuring rotation, $12^{\text {th }}$ question was answered "completely correct" by $41.6 \%(f=52)$ of the students, "partly correct" by $0.8 \%(f=1)$, "wrong" by $24 \%(f=30)$ and left blank by $33.6 \%(f=42)$. More than half of the students answered this question wrongly or left blank. When the category of "partly correct" was studied, although the students determined the correct location the point would be in as a result of $180^{\circ}$ anticlockwise rotation of the given point, they didn't determine the coordinates of the point. When the wrong answers were studied, it was seen that a group of students were mistaken in the application of angle of rotation. While they needed to apply $180^{\circ}$ anticlockwise rotation, they used $90^{\circ}$ anticlockwise rotation. Another group of students made mistakes not only in the angle of rotation but also in the direction of rotation.

Some common examples the student's answer are given in Table 9.

Table 9. Examples from the student's answers

Question10 Wrong




\subsubsection{Findings about Translation}

The findings for the $5^{\text {th }}$ and $14^{\text {th }}$ questions about translation are given in Table 10.

Table 10. The percentage (\%) and frequencies (f) of the students' answers to the question about translation

\begin{tabular}{lllllllll}
\hline & \multicolumn{2}{l}{ Completely correct } & \multicolumn{2}{l}{ Partly correct } & \multicolumn{2}{l}{ Wrong } & \multicolumn{3}{l}{ Blank } \\
\hline & $\mathrm{f}$ & $\%$ & $\mathrm{f}$ & $\%$ & $\mathrm{f}$ & $\%$ & $\mathrm{f}$ & $\%$ \\
Question 5 & 44 & 35.2 & 1 & .8 & 36 & 28.8 & 44 & 35.2 \\
Question 14 & 16 & 12.8 & 2 & 1.6 & 62 & 49.6 & 45 & 36 \\
\hline
\end{tabular}

One of the questions about translation transformation, $5^{\text {th }}$ question was answered "completely correct" by $35.2 \%(f=44)$ of the students, "partly correct" by $0.8 \%$ ( $f=1)$, "wrong" by $28.8 \%(\mathrm{f}=36)$ and left blank by $35.2 \%(\mathrm{f}=44)$. In the fifth question, the students were required to find the coordinates of the new point by translating $N(4,-5)$ point four unit down along the y axis. More than half of the students answered this question wrongly or left blank. The student who answered "partly correct" to the question wrote the coordinates wrongly although he was able to find the point under translation on the coordinate line. It was seen that the students who gave wrong answers generally made translation along the $\mathrm{x}$ axis or made mistakes in the direction of translation.

One of the questions about translation transformation, $14^{\text {th }}$ question was answered "completely correct" by $12.8 \%$ ( $\mathrm{f}=$ 16 ) of the students, "partly correct" by $1.6 \%(f=2)$, "wrong" by $49.6 \%(f=62)$ and left blank by $36 \%(f=45)$. In this question, the students were asked what the new coordinates should be when $\mathrm{M}(-3,0)$ point was translated 5 units right along the $\mathrm{x}$ axis. The total percentage (85.6\%) of the wrong or blank answers makes up more than half of the students' answers. When "partly correct" answers were studied, it was noticed that the coordinates asked in the question were found wrong with a difference of one unit. When the "wrong" answers were studied, it was seen that the students generally added to the $\mathrm{y}$-axis component while applying 5 units right of translation and the students adding to the $\mathrm{x}$-axis coordination made mistakes in the operation of addition in negative numbers.

The examples from the common mistakes the students made are given in Table 11.

Table 11. Examples from the student's answers

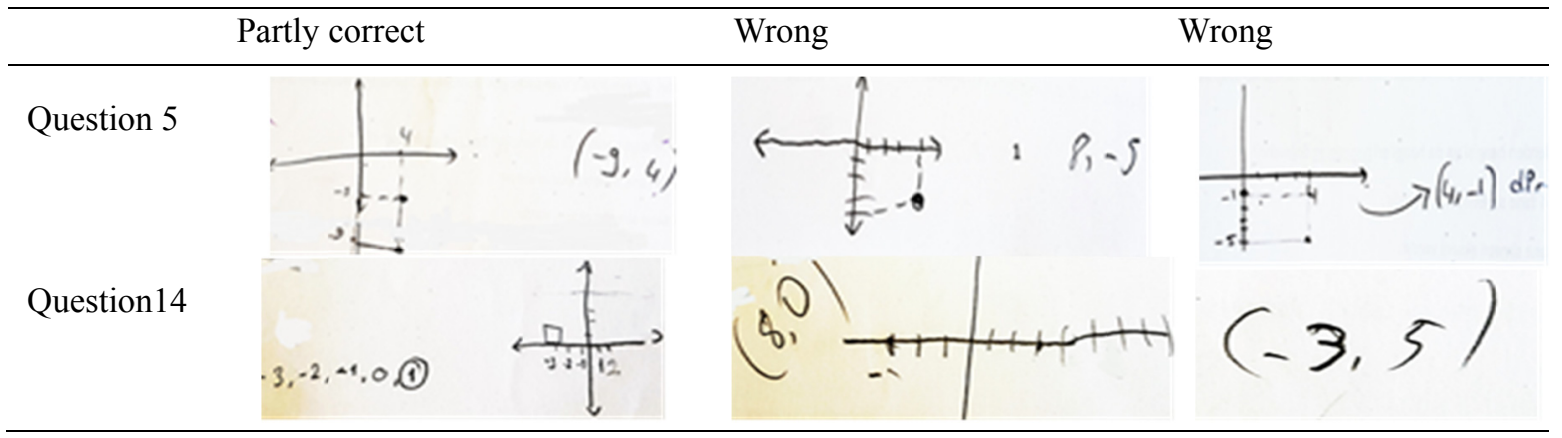

\subsection{Findings about Multiple Choice Test Items}

The answers given for the multiple-choice test items in the concept test of transformation geometry were coded as "wrong" or "correct" and turned into a table by regarding the blank answers as "wrong".

Table 12. The percentage (\%) and frequencies (f) of the students' answers to the question about multiple choice questions

\begin{tabular}{|c|c|c|c|c|c|c|c|c|c|c|c|c|c|c|}
\hline & \multirow{2}{*}{\multicolumn{2}{|c|}{ Correct }} & \multirow{2}{*}{\multicolumn{2}{|c|}{ Wrong }} & \multicolumn{10}{|c|}{ Wrong Answer Offers } \\
\hline & & & & & \multicolumn{2}{|c|}{ A } & \multicolumn{2}{|c|}{$\mathrm{B}$} & \multicolumn{2}{|l|}{$\mathrm{C}$} & \multicolumn{2}{|l|}{ D } & \multicolumn{2}{|c|}{ Blank } \\
\hline & f & $\%$ & f & $\%$ & f & $\%$ & f & $\%$ & f & $\%$ & $\mathrm{f}$ & $\%$ & $\mathrm{f}$ & $\%$ \\
\hline Q1 & 35 & 28 & 90 & 72 & 23 & 18.4 & & & 24 & 19.2 & 33 & 26.4 & 10 & 8 \\
\hline Q2 & 87 & 69.6 & 38 & 30.4 & 18 & 14.4 & 4 & 3.2 & 15 & 12 & & & 1 & 0.8 \\
\hline Q4 & 80 & 64 & 45 & 36 & & & 20 & 16 & 18 & 12,8 & 5 & 4 & 2 & 1.6 \\
\hline Q6 & 83 & 66.4 & 42 & 33.6 & & & 37 & 29.6 & 3 & 2.4 & 0 & 0 & 2 & 1.6 \\
\hline Q7 & 83 & 66.4 & 42 & 33.6 & 18 & 14.4 & & & 5 & 4 & 13 & 10.4 & 6 & 4.8 \\
\hline Q9 & 74 & 59.2 & 51 & 40.8 & 8 & 6.4 & 22 & 17.6 & & & 10 & 8 & 11 & 8.8 \\
\hline Q15 & 101 & 80.8 & 24 & 19.2 & 3 & 2.4 & 13 & 10.4 & & & 8 & 6.4 & 0 & 0 \\
\hline Q16 & 69 & 55.2 & 56 & 44.8 & 11 & 8.8 & 4 & 3.2 & 39 & 31.2 & & & 2 & 1.6 \\
\hline
\end{tabular}

When the answers given for the multiple test questions were analysed, it was noticed that the first test item was a question that the students were able to comment with their information about symmetry (symmetry axis) in a line. 35 students $(28 \%)$ answered correctly to this test question and 90students (72\%) made it wrong. These findings show that 
the students had some deficiencies in determining the symmetry axis of geometric shapes. When the "wrong" answers were studied, it was seen that the students mostly preferred to mark D choice. A student who could find three symmetry axes of equilateral triangle couldn't show the same success in for a pentagon. A part of the interviewed made with S8 is given below.

S8: Now, sir, it says here a rectangular has four symmetries. (He draws a rectangular shape on the blank place of the paper. By finding the common points of long and short sides on the rectangular he drew) one, two (by drawing lines from the diagonals) this isn't exact as such. It becomes two shapes. Since the question always us the right ones, this is wrong.

Researcher (R): Yes, what do you think about the second item?

S8: (by reading the second item of the question) there are five symmetry axes of a pentagon (he drew a pentagon on the blank side of the paper. By drawing a line from the top to down) it has only one (by trying to conjoin the other corner points with not neighbouring with themselves). Nothing else is possible. This is wrong too. The symmetry axis of a pentagon is not five.

$R$ : Do you think you have found all possible symmetry axes?

S8: Yes, teacher.

$R$ : What do you think about the other items?

S8: An isosceles triangle has two symmetries (by drawing an isosceles triangle, he drew the top as median and counted the segments that this line divided) there is one, two symmetry axes. It is right. An equilateral triangle has three symmetry axes (by drawing a equilateral triangle, he drew medians from each corner). Like this, one, like this two, and like this three. It is right so I marked the choice including II and III items.

Although S8 said that the statement "the pentagon including in the second item of the first question has five symmetry axes" was wrong, he made mistake while marking the test choice. In the interviews done, it was seen that the students gave wrong answers since they couldn't explore the connection of side and symmetry axis in regular polygons.

The second test item is connected with measuring the information about symmetry in a line. In this questions, the students were required to find the right choice from the new appearing words when given words were transformed according to symmetry axis. 87 students $(69.6 \%)$ answered correct and 38 of them (30.4\%) marked the wrong answer for this test item. This finding shows that majority of the students succeeded in taking symmetry of the given shape in vertical line. When table 9 was studied, it was noticed that a mistake was made in choice A of the question. This arises from "S" letter in the choice. A part of the interview made with $\mathrm{S} 2$ is given below.

\section{$R$ : Why did you mark choice A for this question?}

S2: (pointing the choice A in which the word SOS was given in the question in vertical symmetry axis under reflection and of which image was also given as SOS) I noticed these overlap one another.

$R$ : You accepted the right answer was A, by thinking they overlap one another.

S2: Yes

A: Well, what if I wanted you to draw the image of " $S$ " letter under reflection. What kind of a thing would you draw?

S2: Umm, actually, when we fold choice A, the shapes don't overlap one another.

$R:$ Well, which one is the correct choice?

S2: D choice

R: How did you think about?

S2: When I fold the paper, the shapes overlap.

The fourth question is a question that the students could solve with their information about symmetry in a line. In this question, the students were required to find the result of the operation among the new numbers appearing when 22-5 operation was subjected to reflection in vertical symmetry line. 80 students (64\%) marked the correct choices and 45 students (36\%) made wrong in this test item. When the students' answers were studied, it was seen that the students intensively marked B (-17) and C (17) choices. These mistakes generally arose from the fact that the image of number 22 taken under reflection in vertical symmetry axis was also taken as number 22 . They couldn't use the information that a point taken on the given shape during reflection should be at equal distance with vertical symmetry axis. A part of the interview made by $\mathrm{S} 9$ is given below.

S9: (he found the symmetry as 5-22 in the answer sheet) If I thought this as 22, 22 minus 5, it is 17. If I thought 55 
instead of 22. 55 minus 5 , it is -50 .

\section{$R:$ What should you pay attention while making reflection?}

S9:( by pointing the extreme point of 5 on the shape, meaning its distance to symmetry axis) here, there are two steps, we should draw two more steps in other side too. (taking another point and determining the distance of vertical axis of this point) and here is three steps. 1,2,3. If we draw on the other side.

\section{$R$ : Which number became the reflecting shape?}

S9: 5

As seen in the dialogue above, the student was aware of the fact that the image of the shape occurring as a result of reflection should be at equal distances with symmetry axis, but nevertheless, he couldn't draw the right shape

The $6^{\text {th }}$ test item was about measuring the information of whether the given shape included axes of symmetry, that is, the given shape was symmetric or not. The students were expected to answer as "correct" or "wrong" for the judgements in the way of symmetric or assymetric which were given for $\mathrm{V}, \mathrm{G}$ and $\mathrm{F}$ letters in the question. 83 students (66.4\%) answered correctly and 42 students (33.6\%) made wrong in this test item. When studied the students' answers, they intensively stated choice B, that is, they told two of them from the judgements were wrong. A part of the interview made by $\mathrm{S} 11$ is given below.

S11: (after reading the question) is $V$ symmetric or assymetric? (drawing a V letter on to the blank place of the sheet) I think that is not symmetric.

\section{R: Is V assymetric? Why?}

S11: (meaning the right and left side of the letter) because if you look over Vletter from here or look from the other side, $V$ is the same. That's why it is not symmetric. G letter could be symmetric. G letter is symmetric, it is right. (in the table, $G$ letter was marked as symmetric) F letter, this is also symmetric. (in the table, G letter was marked as asymmetric)

The student couldn't improve a perception in deciding whether a given shape or a structure is symmetric or not.

In the $7^{\text {th }}$ test item, the students were required to determine the horizontal and vertical symmetry axes for the given syllables. And for this to happen, it was important they determined the horizontal and vertical symmetry axes of the syllables. 83 students $(66.4 \%)$ answered correctly and 42 students $(33.6 \%)$ marked the wrong answers in this question. When the students' wrong answers were studied, it was noticed that they fell into mistake generally for A (BOB) and D choices (TOT). Part of the interview made with the S7 is given below.

\section{$R$ : let us look the question 7. Why did you mark the B?}

S7: This has got symmetry (pointing the choice he marked), as horizontally.

$R$ : Yes, the question asks if there are horizontal or vertical symmetry axes in the question. You said there was horizontal symmetry axis, is there any vertical symmetry?

S7: yes, it is.

S7 made mistake about that fact that the direction of the letters in the vertical symmetry axis should look one another, that is, the points taken on the letter to the vertical axis should be at equal distance.

With the $9^{\text {th }}$ test item, new shape and position occurring as a result of rotation in specific angles according to the reference point being not on the given geometric shape was aimed to determine. 74 students $(59.2 \%)$ answered correct and 51 students $(40.8 \%)$ made wrong in the test item. The wrong answers mostly intensified on the choice B. A part of the interview made with $\mathrm{S} 1$ is given below.

\section{$R$ : Could I learn your thinking style in the solution of the $9^{\text {th }}$ question?}

S1: I tried the choices one by one. If the first shape is rotated $270^{\circ}$ degrees clockwise (by rotating the paper 270 degree), the shape stays at the bottom side. If the second shape is rotated 180 degrees anti-clockwise, (again he rotated the paper by sliding it on the table) the shapes come side by side.

$\mathrm{S} 1$ tried the rotation to become more concrete by rotating the paper. The mistake he did here was not the side by side position of the shapes, but not able to predict the direction of theirs.

In the $15^{\text {th }}$ test item, it was aimed to determine the image under reflection in oblique symmetry axis of the given geometric shape. 101 students $(80.8 \%)$ answered correct, but 24 students $(19.2 \%)$ answered wrong in this question. The wrong answers mostly intensified on the choice B.A part of the interview made with S9 is given below.

$R$ : Let's look over the answer for the $15^{\text {th }}$ question.

S9: Here, the symmetry of the given shape was asked. I did B. 


\section{R: Why did you choose B?}

S9: First, I looked at the dimensions of the shapes. When we look at the dimensions, the choice A and the dimension of the given shape are not the same. Therefore, I eliminated it. In D, the dimensions are the same, but when I fold the paper, the shapes don't overlap, so I deleted it.

$R$ : Yes

S9: First, I marked C, but it seems as if the dimensions are different.

That's why I marked B.

R: Did you eliminate C only because its dimensions are different?

S9: Yes

$R:$ Well, when we analyse about the position and direction, what can you tell about?

S9: (by wrapping the paper vertically) the choice D becomes the answer.

$R$ : Is the line you have wrapped a symmetry axis for this question?

S9: Not A. The choice C looks more similar.

As can be understood from the part above, S9 benefitted the property that the reflection keeps the dimension of the shape while solving the question. He didn't focus on the change the reflection made on the properties of the position and direction. He didn't pay attention that the symmetry axis was the oblique symmetry axis.

The $16^{\text {th }}$ test item aimed to determine at the result of which of the translation activities the given geometric shapes formed. 69 students $(55.2 \%)$ gave the correct answer and 56 students $(44.8 \%)$ made wrong in this question. The wrong answers intensified on the choice C. A part of the interview made with S4 is given below.

\section{$R$ : Let's look over the 16. question together.}

S4: I studied the choices. In the choice of A, it says to us to translate A three units down and three units left. This is gone. In the choice of $C$, I found the shape by translating $A$ three units down and two units right.

As seen from the answer S4 gave in the table 1, he couldn't see that the remaining distance in the base length of the triangle is two units. When studied the other students' answers, it was observed that during the translation the

based points showed differences while finding the shape after transformation.
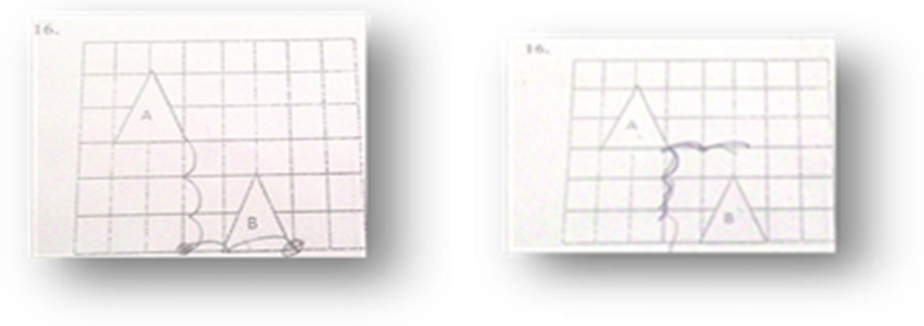

Figure. Different answers to question 16

\section{Results and Discussions}

About the translation; two results were reached in the study. The first one is that the students were aware of the fact that the translation transformation is a concept of replacement, but they made mistakes on the issue of replacement direction (e.g. along the $\mathrm{x}$-axis or $\mathrm{y}$-axis) while translating a given point in the coordinate system.

Secondly, some mistakes such as matching the based point with a different point as shape while finding the image of a closed shape under translation were made. The reason why the students couldn't take the image of the based point under translation could result from the fact that they couldn't isolate these transformations were isometry. In the study of Portnoy, Grundmeier and Graham (2006), they mention about the fact that the isometric properties of translation, reflection and rotation couldn't be isolated by the students. Isometric properties are finding the remaining properties after these transformations. For instance, in the translation transformation, if and how many units of translation will be done should be as the translation of all the points of the given shape as the given unit. Besides, another reason why the students found the wrong points of the new shape when a closed shape was translated might be because of the fact that they couldn't understand the necessity to direct the translation based on a vector. In a study which Yanik and Flores (2009) made with a teacher, they wanted the teacher candidate to make translation of a closed shape. They stated that the candidate firstly thought the translation as a movement and changed its position. With the given educational courses, 
they provided acquisitions to teach that translation transformation is a mapping based on a vector. Using vector parameters while finding the image of the points of a given shape under translation could provide a possibility in which the students could match the points properly.

About the reflection; six results were reached in the study. First of all, when the students were required to study the given two shapes in terms of being the image under reflection of one another, it was seen that they could mostly answer correctly based on the fact that the dimensions would be the same under reflection. However, some of the students made mistakes by developing a misconception that the shape of the image should be identical instead of being similar.

Secondly, the students fell into mistakes because they couldn't utilize the information that the image could be taken by determining a point at equal distance to vertical symmetry axis after transformation of any of the given letters and numbers in a vertical line under reflection. Yavuzsoy Köse (2012), pointed out that the students made mistake since they didn't pay attention to the equal distances in symmetry line. The reasons of this mistake result from the fact that the students either made mistakes in determining the equal distances or couldn't perceieve the comprehension of the preservation of the distance under reflection (Hansen, 2005).

Thirdly, it was seen that while finding the image of the given shape under reflection according to the origin point in coordinate system, they couldn't use the preservation property of the reflection and couldn't develop the comprehension that the points of the shape corresponding on to axis would again stay on the reflection. This finding obtained in the study, matches up with the result that extra shapes were drawn or it was ignored the image of a shape cutting the horizontal symmetry axis under reflection cut the axis in the study of Yavuzsoy Köse (2012).

Fourthly, it was noticed that since the students thought the reflection as translation transformation, they made no change towards the direction, except of changing the position. Likewise, in previous studies, It was found that the students couldn't recognize the concept of reflection and translation, confused both of the concepts with one another thus having difficulties (Kaplan \& Öztürk, 2014; Köse, 2012).

The fifth result about reflection is that the students made mistakes in determining the point in the way of cutting the symmetry axis vertically and being at equal distances between the first point and symmetry axis while finding the image of the point taken on the shape under reflection. The students in general couldn't find the image of the based point in the way that would cut the symmetry axis vertically in the application of reflection in oblique symmetry line. The reason why they made such mistakes arises from the fact that oblique symmetry axis was more difficult than horizontal and vertical symmetry axes and that they couldn't succeed in cutting the oblique symmetry axis vertically (Hansen, 2005).

Sixthly, about finding the symmetry axis of the closed shapes; while they were finding the symmetry axis of parallelogram, they made mistakes thinking there were two symmetry axes by drawing the lines of diagonal. The reason why they had this misconception could result from the discourses often used by the teachers such as the lines cutting two equal parts while symmetry axis was being found in the reflection transformation (Hansen, 2005). This provides the students to develop the idea that if the closed shape is cut into two equal parts, one of its part is the reflection of the other part. In the study of Hacisalihoğlu-Karadeniz et al. (2015) they pointed out that the candidate teachers had the same misconceptions and this would also affect their students when they became teachers. Likewise, Son (2006) stated that the teacher candidates had some misconceptions such as thinking a parallelogram has symmetry axis It was observed that the students fell into conceptual mistakes since they couldn't explore the connection between side and symmetry axis in regular polygons. In the studies of Yavuzsoy Köse and Özdaş (2009), they pointed out that by using Cabri Geometry software, they could explore the linear connection between the number of sides and symmetry axis of the regular polygons, that is, the existence of as many symmetry lines as the number of sides in regular polygons. It is thought that when the students are involved in the activities whereby they could explore the connections; it could be prevented for them to fall into such mistakes.

About the rotation; They got difficulties in finding the rotation angle and also in the direction of the rotation. While the students were making rotational transformation, they generally moved the question sheet on the desk they sat. Even thought it was a practical method in order to concretize the transformation, it could turn out to be a situation preventing the improvements of imagining, thinking visual and spatial skills. The fact that the students were not adequately improved in thinking visual and spatial can be shown the source of these mistakes. The student who perceives the linear shapes as a whole in the comprehension of solids as conceptually can picture them in his mind afterwards, and after he applied reflection, rotation and translation to the abstract things he has pictured, he could switch into a geometrical dimension. This can improve the student's spatial thinking skill.

\section{Recommendations}

According to the results obtained from the study, it was detected that the students participated in the study had some difficulties in reflection, rotation and translation and made mistakes. The teachers taking charge in learning 
environments towards overcoming these difficulties should create learning environments which can improve the skill of conceptual information in teaching reflection, rotation and translation and improve the skill of practicing these concepts. For this, the translation could be shown as though it moves with the help of polygon and acetate on the paper. The translation can be applied by copying the white paper below on acetate (Zembat, 2013). In teaching, some activites such as the usage of symmetry mirror, butterflies, people, vehicles, a half-cut shape of an object and the reflection of the image to the water can be linked with life, besides it is quite important for the students' comprehension of concepts to make activities such as making the students find the transformations in art works. In teaching rotational transformation, using the softwares like Logo, Cabri, GeoGebra and Geometer's Sketchpad (Baki, 2002; Knuchel, 2004; Hollebrands, 2003; Yavuzsoy Köse \& Özdaş, 2009; Hoyles \& Healy,1997) are recommended since they could take the students' attraction and also provide the conceptual learning.

According to the results of the study, the writers of coursebooks can teach the topics of transformation geometry in their lessons so that they could minimize the students' making mistakes. Some activities could be included in the coursebooks for conteptual learning of these topics.

\section{Acknowledgements}

\section{CONCEPT TEST OF TRANSFORMATION GEOMETRY (multiple choices )}

Dear friends, this test is designed to identify possible misconceptions about your transformation geometry. You are required to make the solution by explaining the questions that are requested from you to the vacancy given below. Your identity will remain completely confidential. It is purely for research purposes, it has no note value.

1. Which of the following informations is always true?

I. The rectangle has four symmetry axes.

II. The pentagon has 5 symmetry axes.

III. The isosceles triangle has two symmetry axes.

IV. The equilateral triangle has three symmetry axes.
A) II VE III
B) II VE IV
C) II, III ve IV
D) IV

2. Which of the words given below is correct the reflected according to axis?

4.

A)

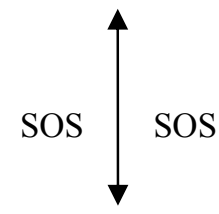

B)

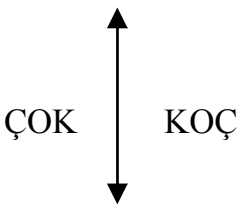

C)

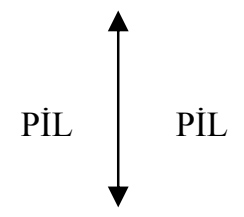

D)

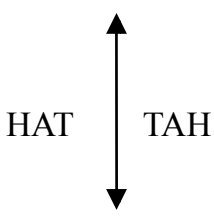

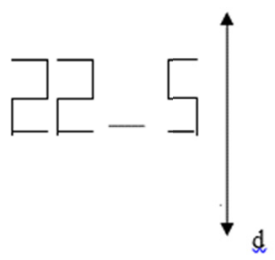

The following process is taking the reflection according to $d$ line. What is the result of the new process to be created?
A) -53
B)-17
C) 17
D) 20

6.

\begin{tabular}{|l|l|l|}
\hline Letters & Symmetrical & Non-symmetrical \\
\hline $\mathbf{V}$ & $\mathbf{X}$ & \\
\hline $\mathbf{G}$ & $\mathbf{X}$ & \\
\hline $\mathbf{F}$ & & $\mathbf{X}$ \\
\hline
\end{tabular}

The letters in the table are evaluated according to their symmetrical and non-symmetrical nature. How many places have been marked incorrectly?
A) 1
B)2
C) 3
D) 0 
7. Which of the following words have both horizontal and vertical symmetry axes?
A) $\mathrm{BOB}$
B) $\mathrm{HOH}$
C) KOK
D) TOT

9.

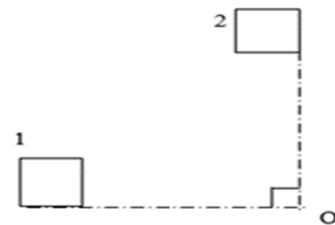

Identical squares with equal distances to the shaped $\mathrm{O}$ point are around the $\mathrm{O}$ point; If the first is rotated $270^{\circ}$ clockwise and the second is rotated $180^{\circ}$ clockwise, which form the following forms?
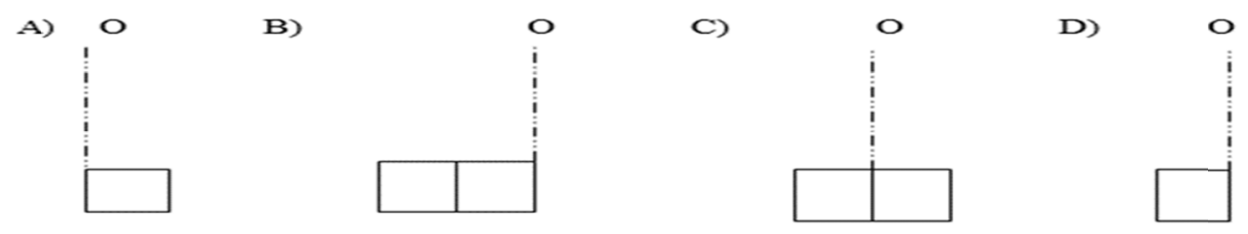

15.

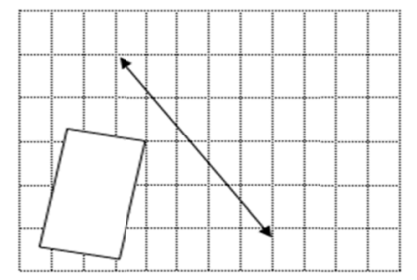

Which of the following is the image under the reflection transformation mode given to the focal plane?

A)

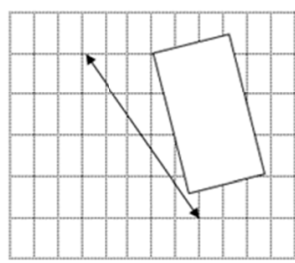

16.

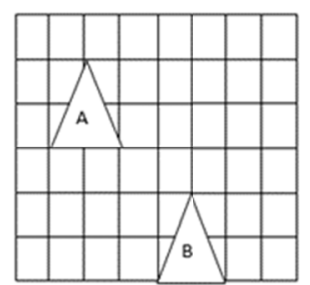

B)

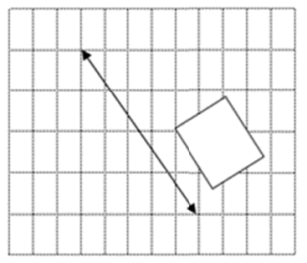

C)

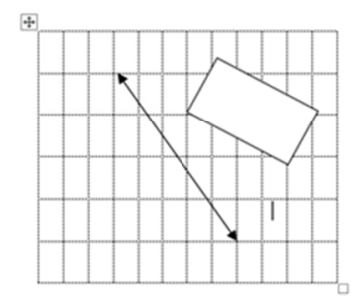

D)

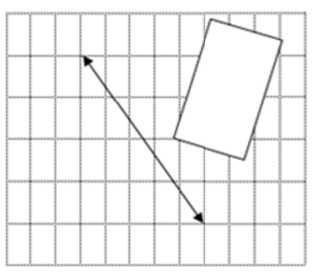

On the unit squares, the shape $\mathrm{A}$ is obtained in the form of $\mathrm{B}$. Which of the following describes this situation?
A) By shifting A three units down, three units to the left.
B) By shifting A two units down, three units' right
C) By shifting A three units down, two units by right
D) By shifting A by three units down, three units by right

\section{References}

Aksoy, Y., \& Bayazit, İ. (2009). Simetri konusunda karşılaşılan zorluklar. In Bingölbali, E. \& Özmantar, M.( Eds), İlköğretimde karşılaşılan matematiksel zorluklar ve çözüm önerileri (pp. 187-215). Ankara: Pegem A Publications.

Baki, A. (2002). Öğrenen ve ögrretenler için bilgisayar destekli matematik. İstanbul: Uygun Basın ve Tic. Ltd.Şti.

Baykul, Y. ( 2009). İlköğretimde matematik ögrretimi 6-8. siniflar. Ankara: Pegem A Publications. 
Bingölbali, E., \& Özmantar, M. (2009). Matematiksel kavram yanılgıları: sebepleri ve çözüm arayışları. In Bingölbali, E. \& Özmantar, M. (Eds), İlköğretimde karşılaşılan matematiksel zorluklar ve çözüm önerileri (pp. 187-215). Ankara: Pegem A Publications.

Bingölbali, E., Şandır, H., \& Delice, A. (Eds) Tanımları ve tarihsel gelişimleriyle matematiksel kavramlar (pp. 613-628). Ankara: Pegem A Publications.

Burton, D. M. (2011). The history of mathematics: an introduction (Seventh Edition). New York, NY: McGraw-HillCompanies, Inc.

Büyüköztürk, Ş., Çakmak, K. E., Akgün, Ö., Karadeniz, Ş., \& Demirel, F. (2012). Bilimsel araştırma yöntemleri (11. bask1). Ankara: Pegem A Publications.

Conway, J. H., Burgiel H., \& Strauss, G. C. (2008). The symmetries of things. A K Peters, Ltd. Wellesley.

Creswell, J. W., \& Plano, C. V. L. (2015). Karma yöntem araştırmaları tasarımı (Y. Dede \& S.B.Demir, Translation. Eds). Ankara: Anı Publications.

Dodge, C. W. (2012). Euclidean geometry and transformations. New York, NY: Courier Dover Publications.

Edwards, L. (2003). The nature of mathematics as viewed from cognitive science. Paper presented at the Third Congressof the European Society for Research in Mathematics, Bellaria, Italy. Retrieved from http://fibonacci.dm.unipi.it/cluster-pages/didattica/CERME3/proceedings/Groups/TG1/TG1_edwards_cerme3.pdf

Elby, A. (2001). Helping physics students learn how to learn. American Journal of Physics, Physics Education Research Supplement, 69(1), 54-64. https://doi.org/10.1119/1.1377283

Ersoy, Y. (2006). Innovations in Mathematics Curricula of Elementary Schools-I: Objective, Content and Acquisition. Elementary Education Online, 5(1), 30-44.

Fisher, K. (1983). Amino acids and tranlation: A misconceptions in biology. In H. Helm J.Novak (Eds.), Proceedings of the International Seminar on Misconceptions in Science and Mathematics (pp. 407-419). Ithaca, NY: Department of Education Cornell University.

Hacısalihoğlu-Karadeniz, M., Baran, T., Bozkuş, F., \& Gündüz, N. (2015). Difficulties of prospective elementary mathematics teachers' regarding to reflection symmetry. Turkish Journal of Computer and Mathematics Education (TURCOMAT), 6(1), 117-138. https://doi.org/10.16949/turcomat.71538

Hansen, A. (2005). Shape and space. In Hansen. A. (Ed) Children's rrors in mathematics: understanding common misconceptions in primary schools (pp.76-102). Learning Matters: British Library Cataloguing in Publication Data.

Hollebrands, K. (2003). High school students' understandings of geometric transformations in the context of a technological environment. Journal of Mathematical Behavior, 22(1),

55-72. https://doi.org/10.1016/S0732-3123(03)00004-X

Hoyles, C., \& Healy, L. (1997). Unfolding meanings for reflective symmetry. International Journal of Computersfor Mathematical Learning, 2(1), 27-59. https://doi.org/10.1023/A:1009721414546

Kaplan, A., \& Öztürk, M. (2014). Analysis of 2nd-8th grade students' thinking approaches toward understand the concept of symmetry. Elementary Education Online, 13(4), 1502-1515.

Knuchel, C. (2004). Teaching symmetry in the elemantary curriculum. The Montana Mathematics Enthusiast, 1(1), 3-8.

Martin, G. (1982). Transformation geometry: an introduction to symmetry. New York: Springer

Miles, B. M., \& Huberman, A. M. (1994). Qualitative data analvsis (2nd edition.). London: Sage Pub

Ministry of National Education [MoNE] (2013). Ortaokul matematik dersi (5, 6, 7 ve 8.sinfflar) öğretim programı. Ankara: MEB. https://doi.org/10.1007/978-1-4612-5680-9

National Council of Teacher of Mathematics (NCTM,1991). Professional standarts for teaching mathematics. Reston, Va: NCTM.

Portnoy, N., Grundmeier T. A., \& Graham, K. J. (2006). Students' understanding of mathematical objects in thecontext of transformational geometry: Implications for constructing and understanding proofs. Journal of Mathematical Behavior, 25, 196-207. https://doi.org/10.1016/j.jmathb.2006.09.002

Ryan, J., \& Williams, J. (2007). Children's mathematics, 4-15: Learning from errors and misconceptions. New York: Open UniversityPress.

Skemp, R. R. (1976). Relational understanding and instrumental understanding. Mathematics Teaching, 77, 20-26. 
Smith, J., Disessa, A., \& Roschelle, J. (1993). Misconceptions reconceived: A constructivist analysis of knowledge in transition. The Journal of the Learning Sciences, 3, 115-163. https://doi.org/10.1207/s15327809jls0302_1

Son, J. W. (2006). Investigating preservice teachers' understanding and strategies on a student's errors of reflectivesymmetry. In Novotná, J., Moraová, H., Krátká, M. \& Stehlíková, N. (Eds.). Proceedings 30th Conference of the International Group for the Psychology of Mathematics Education, 5, 145-152. Prague: PME.

Ubuz, B. (1999). 10th and 11th grade students errors and misconceptions on basic geometry. H. U. Journal of Education, 1716-17, 95-104.

Ülgen, G. (2001). Kavram geliştirme. Ankara: Pegem A Publications.

Van de Walle, J.,Karp, K.,\& Bay-Williams, J. (2012). Illkokul ve ortaokul matematiği: gelişimsel yaklaşımla öğretim. (Translation. Ed. Soner Durmuş). Ankara: Nobel Publication.

Yanik, H. B., \& Flores, A. (2009). Understanding rigid geometric transformations: Jeff's learning path for translation. The Journal of Mathematical Behavior, 28(1), 41-57.https://doi.org/10.1016/j.jmathb.2009.04.003

Yavuzsoy, K. N. (2012). Primary school students' knowledge of line symmetry, H. U. Journal of Education, 42, 274-286.

Yavuzsoy, K. N. (2013). Geometrik dönüşümlerden biri: Yansıma dönüşümünü anlamak. In Zembat,İ.,Ö, Özmantar, M.,F., Bingölbali, E., Şandır, H. Ve Delice, A.(Eds) Tanımları ve tarihsel gelişimleriyle matematiksel kavramlar (pp. 613-628). Ankara: Pegem A Publications.

Yavuzsoy, K. N., \& Özdaş, A. (2009). How do the fifth grade primary school students determine the line of symmetry in various geometrical shapes using Cabri Geometry software? Elementary Education Online, 8(1), 159-175.

Zembat, I. O. (2008). Kavram yanılgısı nedir? In M. F. Özmantar, E. Bingölbali, ve H.Akkoç (Ed.), Matematiksel kavram yanılgıları ve çözüm önerileri, (pp. 1-8). Ankara: Pegem A Publications.

Zembat, İ., Ö. (2013). Geometrik dönüşümlerden öteleme ve farklı anlamları. In Zembat, İ.,Ö, Özmantar, M.,F., Bingölbali, E., Şandır, H. Ve Delice, A.(Eds) Tanımları ve tarihsel gelişimleriyle matematiksel kavramlar (pp. 613-628). Ankara: Pegem A Publications.

\section{Copyrights}

Copyright for this article is retained by the author(s), with first publication rights granted to the journal.

This is an open-access article distributed under the terms and conditions of the Creative Commons Attribution license which permits unrestricted use, distribution, and reproduction in any medium, provided the original work is properly cited. 